\title{
Multiple breath helium dilution measurement of lung volumes in adults
}

\author{
R. Brown*, D.E. Leith**, P.L. Enright ${ }^{+}$
}

\section{CONTENTS}

Equipment

247

Procedure and calculation .................................... 247

Calculations .......................................................... 248

Reproducibility and needs for duplicate analyses.. 249

Paths of helium loss and effects of nitrogen

excretion.

249

Other factors affecting helium concentration ...... 250

Switching error and changes in lung spirometer

volume during the test
Quality control

252

Daily quality control checks

Weekly quality control checks

252

Linearity checks ............................................ 252

Biological checks ........................................... 253

Cross contamination …...................................... 253

Comparison of the helium dilution method and

body plethysmography ...................................... 253
This manuscript recommends techniques (methodology) for the measurement of total lung capacity (TLC), functional residual capacity (FRC) and residual volume (RV) in adults using the closed-circuit helium dilution method. Lung volumes were first measured using a hydrogen gas dilution technique about $200 \mathrm{yrs}$ ago. Helium replaced hydrogen for safety reasons 40-50 yrs ago when clinicians started to use the test [1]. Since its description in 1940, the nitrogen washout method has been shown to give results equivalent to the helium dilution technique in patients and to body plethysmographic techniques in healthy subjects [2-12].

The American Thoracic Society (ATS) has not recommended standards for the measurement of lung volumes but the European Coal and Steel Community (ECSC) did so for the helium dilution method in 1983 [13] and the European Respiratory Society (ERS) endorsed the 1993 update of these European standards [14]. The following recommendations are compatible with (and do not contradict) the 1995 ATS spirometry and diffusion capacity standards [15, 16] and the 1993 ERS standards for helium dilution tests.

Formation of these new standards required a balance between: 1) accommodating an established base of older instruments using traditional manual techniques; and 2) requiring the development and purchase of expensive new automated, computer-controlled instruments with exten- sive new quality assurance programmes. The compromises reached here mean that a few older instruments will need complete replacement and many existing automated instruments will require inexpensive software upgrades in order to meet the minimum standards.

A few commercially available systems use innovative or alternative techniques, which have potential advantages (e.g. convenience, rapidity and accuracy) over the standard techniques given in this document. The authors of this document wish to encourage such innovation; however, it is the responsibility of manufacturers to demonstrate that the lung volumes reported by such new instruments do not vary substantially from those obtained by the standard techniques, or that they are more accurate. It is important to recognize that such comparisons must be made using normal subjects as well as patients with varying kinds and severities of disease.

We are in agreement with many of the standards recommended by the ERS and, to avoid merely restating these, have reproduced (with permission) much of what the Society published previously [14]. Substantive differences, where they exist, have been added to the description of the method, and a detailed section on problems and controversies has been added. Technical specifications are within the capacity of most existing equipment. Many specifications are based on published recommendations. Some have been arrived at by empiric testing in

\footnotetext{
*Pulmonary and Critical Care Medicine Section, Medical Service, Dept of Veterans Affairs Medical Center, West Roxbury, MA and Dept of Medicine, Harvard Medical School, Boston, MA, USA. **Dept of Clinical Sciences, Kansas State University, Kansas, USA. ${ }^{+}$Respiratory Sciences Center, University of Arizona, Tucson, Arizona, USA.
}

Correspondence: R. Brown, Pulmonary and Critical Care Medicine (111B), VA Medical Center, 1400 VFW Parkway, West Roxbury, MA 02132, USA. Fax: 0016173635670

Keywords: Functional residual capacity, lung volume measurements, residual volume, respiratory function tests, total lung capacity.

Received: August 11 1997; accepted after revision September 71997

This background paper was developed from workshops supported by the American Thoracic Society and the National Heart, Lung and Blood Institute (Conference Grant No. R13HL48384-01) 
manufacturers' laboratories, and a few are based on experience of the authors and others. Practical recommendations have been made. In individual laboratories using other methods, steps should be taken to ascertain whether they yield data within the guidelines.

\section{Equipment}

The widely used multibreath helium equilibration method is based on equilibration of gas in the lung with a known volume of gas containing a known amount (or fraction) of helium $[1,17,18]$. For systems that utilize a spirometer, the spirometer capacity should be 7-10 L with $3 \%$ or better static volume accuracy over the entire range and resolution should be $25 \mathrm{~mL}$ or better. Either water-seal or dry-seal models may be used (maintenance requirements differ). Equipment volume ( $\mathrm{Veq})$, defined as the gas volume in the equipment with the bell at zero volume, including the breathing circuit tubing to the mouthpiece valve, should be no more than about 3.5 L. In general, the smaller the Veq, the larger the changes in helium concentration during measurement of FRC and the smaller the random errors relative to the signal. Equipment in which the spirometer is too small will not accommodate the vital capacity (VC) of adults. The equipment specifications and procedures recommended here establish an advantageous starting helium concentration near full scale deflection of the meter (see below). The mouth pressure needed to initiate a change in spirometer volume should be less than $0.03 \mathrm{kPa}$. It should be easy to pressurize the spirometer to $4 \mathrm{cmH}_{2} \mathrm{O}$ or more to check for leaks. This is a much greater pressure than that which occurs in the spirometer during the test. The spirometer should be equipped with a gas circulation pump, carbon dioxide and water absorbers, an oxygen supply and gas inlet and outlet. The mixing fan should completely mix the gas throughout the circuit within about $8 \mathrm{~s}$ after the end of exhalation into the circuit. Typically, breathing circuit flows of about $50 \mathrm{~L} \cdot \mathrm{min}^{-1}$ are required. This ensures adequate mixing for helium concentration measurements, which are reported every $15 \mathrm{~s}$. Pneumotachometers or other flow devices may be used instead of spirometers. If such devices are not isolated from the respired gas (e.g. by bag-in-box systems), then appropriate calibrations and corrections must be made for changes in gas properties.

A thermal conductivity helium analyser is the type utilized most commonly. However, other types of helium analysers may be used [19] and other inert gases may replace helium [20-22]. The helium analyser should have a range of about $0-10 \%$ helium, a resolution of $0.01 \%$ helium or better over the entire range and a $95 \%$ response time of less than $15 \mathrm{~s}$ to a $2 \%$ step change in helium concentration. The meter should be stable (drift of $0.02 \%$ or less) for measurement periods of up to $10 \mathrm{~min}$. These technical standards are compatible with the recommendation that helium concentration be measured every $15 \mathrm{~s}$ and with the definition of "equilibration" discussed below.

For systems in which inspiratory oxygen fraction $\left(\mathrm{FI}, \mathrm{O}_{2}\right)$ changes substantially during measurement of FRC, the helium meter should be calibrated over the range of $\mathrm{FI}, \mathrm{O}_{2}$ encountered. Temperature in the system should be monitored and should be relatively constant as the helium ana- lyser is sensitive to temperature changes. The problems associated with various types of helium analysers can be avoided by the use of a respiratory mass spectrometer.

A small pump samples gas from the breathing circuit downstream from the carbon dioxide absorber, pushes it through a desiccant chamber and the helium analyser and then back into the main circuit [23]; for most analysers, a sample flow of $200 \mathrm{~mL} \cdot \mathrm{min}^{-1}$ is necessary. Changes in the flow of gas through the analyser or in the pressure of gas in the analyser circuit will affect response time or accuracy. Therefore, flow and pressure must be kept constant. Thermal conductivity helium analysers respond to changes in concentration of carbon dioxide, oxygen, nitrogen and water vapour. Therefore, carbon dioxide and water are removed before the sample is introduced into the helium analyser, and it is desirable to keep the oxygen concentration relatively constant (see below).

The activity of the carbon dioxide and water absorbers should be assured before each test. This may be done, for example, by visual or photocell detection of indicator colour changes or by replacing the absorbent after a specified number of tests. The carbon dioxide concentration in the breathing circuit should be kept below $0.5 \%$ during testing to avoid patient discomfort and hyperpnoea and the effects of carbon dioxide on the helium analyser.

When VC and subdivisions thereof are measured, the temperature of gas inside the system lies somewhere between body temperature and pressure, saturated with water vapour (BTPS) and atmospheric temperature and pressure, saturated with water vapour (ATPS) conditions since it is variably affected by exhaled warm gas, room temperature and heat generated by absorption of carbon dioxide in the soda lime canister. The breathing circuit gas temperature should be measured so that these lung volumes can be corrected to BTPS conditions. FRC is corrected to BTPS by another method (see below). The temperature sensor should have an accuracy of $0.5^{\circ} \mathrm{C}$ or better over the range $12-30^{\circ} \mathrm{C}$ and should have a $90 \%$ response time of less than $30 \mathrm{~s}$ to a $5^{\circ} \mathrm{C}$ step change in temperature. These standards are compatible with the temperature changes and time that typically elapses during measurement of expiratory reserve volume (ERV) and VC.

The breathing valve and mouthpiece should have a combined dead space of less than $100 \mathrm{~mL}$ and should be easy to disassemble for sterilization. The size of this dead space should be available from the manufacturer or measured by filling the compartment with water and measuring the volume.

\section{Procedure and calculation}

The activity of the carbon dioxide absorber in the spirometer and of the carbon dioxide and water absorbers in the helium meter line should be checked, and the absorbers changed when appropriate; in addition, the water level should be checked in water-sealed spirometers. Prior to measurements, the helium analyser should be warmed up and the circulating fan turned on. The first step in preparing the equipment for measuring lung volume is to flush the spirometer with ambient air, place the bell in its lowest position and close the circuit. Rolling-seal spirometers should be emptied and then about $1 \mathrm{~L}$ air added. Oxygen is subsequently added so that after all additions of 
gas in the setup procedure, the oxygen concentration will be $25-30 \%$ prior to connecting the patient to the spirometer. Higher values are acceptable. The system is allowed to equilibrate (mix). When a stable helium reading is obtained, the helium meter is adjusted to zero. Then, helium is added to raise the concentration to nearly full scale deflection $(10 \%)$ on the analyser. The initial helium concentration $\left(F_{\mathrm{sp}, \mathrm{He}, 1)}\right)$ is noted, where $F$ is either the reading or the fractional concentration. An additional 2-3 $\mathrm{L}$ of room air is then added (exactly measured with a calibrated syringe) and the second meter reading $\left(F_{\mathrm{sp}, \mathrm{He}, 2)}\right.$ noted when it is stable. If $V_{\mathrm{sp}}$ is the volume of the spirometer prior to this last addition of air, and Vair the precise volume of air added during the last step, then:

$$
V_{\mathrm{sp}}=V_{\mathrm{air}} \cdot F_{\mathrm{sp}, \mathrm{He}, 2} /\left(F_{\mathrm{sp}, \mathrm{He}, 1}-F_{\mathrm{sp}, \mathrm{He}, 2)}\right.
$$

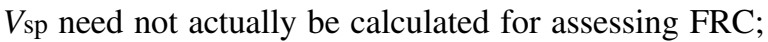
its value is substituted by the right-hand part of equation 1 in computations (see below). If inspiratory vital capacity (IVC) measurements are to be made immediately after the determination of FRC, i.e., before the patient is connected to room air again, then when the patient is at FRC, the volume of gas in the bell should be greater than the patient's inspiratory capacity (IC).

During measurements, the subject should be seated and at rest so that both oxygen uptake and FRC are stable. Dentures need not be removed, but a nose clip should be worn. The subject is connected to the mouthpiece and breathes room air quietly for $30-60 \mathrm{~s}$, so as to become accustomed to the apparatus and attain a stable breathing pattern; then, at the end of a normal expiration, the valve at the mouthpiece is switched to connect the subject to the closed system.

Failure to account properly for the effects of oxygen consumption can result in significant errors in the calculation of lung volumes. During the measurements, oxygen is added by one of the following methods: 1) a constant flow of $100 \%$ oxygen is added to the circuit at a rate determined by an estimate of the patient's oxygen consumption. This estimate is usually $3-4 \mathrm{~mL} \cdot \mathrm{kg}^{-1} \cdot \mathrm{min}^{-1}$ for adults. The equipment should allow and assure oxygen flows up to $500 \mathrm{~mL} \cdot \mathrm{min}^{-1}$; 2) boluses of oxygen can be added as needed (e.g. every 15-30 s) to keep spirometer volume constant at end expiration. Because carbon dioxide is removed from the breathing circuit, the amount of added oxygen approximates the subject's oxygen consumption. The actual volume of oxygen added equals oxygen consumption plus helium absorption minus nitrogen excretion (see below); 3) the third but not commonly used method starts with elevated concentrations of oxygen in the circuit; further oxygen is not added and carbon dioxide is not absorbed during the test. This method can only be used in subjects with rapid equilibration times because rising levels of inspired carbon dioxide may cause the subject to experience breathing discomfort. System volume decreases at a rate equal to the difference between oxygen consumption and carbon dioxide washout leading to an increase in helium concentration and an underestimation of FRC. For short equilibration times, the effect of this is negligible as are the effects of nitrogen excretion and helium absorption (see below). In this method, oxygen concentration is monitored to assure an adequate $\mathrm{F}$, $\mathrm{O}_{2}$ and for correction of the helium meter as described above.
During the equilibration period, the helium concentration is noted every $15 \mathrm{~s}$ and gas mixing considered complete when the decrement in helium concentration is less than $0.02 \%$ in $30 \mathrm{~s}$ (three consecutive readings). As "equilibration" is approached, helium concentration changes are likely to be due mostly to continued gas mixing since the best estimates suggest that helium absorption and nitrogen excretion can cause a change of helium concentration of approximately $0.01 \%$ helium $\cdot \mathrm{min}^{-1}$, equivalent to an increase of about $20 \mathrm{~mL} \cdot \mathrm{min}^{-1}$ in the calculated FRC (Appendix 1). These changes in helium concentration are close to the limit of resolution of modern helium meters. The measurement is continued as long as helium concentration is decreasing by more than $0.02 \%$ in $30 \mathrm{~s}$, equivalent to an increase in calculated FRC of about 80 $\mathrm{mL} \cdot \mathrm{min}^{-1}$ for a typical system testing a person of average size. In systems that report FRC directly, an alternative criterion for ending the test is that the change in FRC is less than $40 \mathrm{~mL}$ per $30 \mathrm{~s}$. We consider that there is no clinical value in prolonging a test after these end-of-test criteria have been met. In practice the test rarely exceeds 10 min even in patients with severe gas exchange abnormalities.

For the measurement of ERV and IVC, if the volume of the spirometer is insufficient, manufacturer instructions should be followed regarding addition of fresh air to the breathing circuit. After the end-of-test criterion is met, stability of FRC should be determined by observing the patient and the display on the computer screen for several breaths. The patient should then be instructed to exhale slowly and fully to RV. Variation in respiratory system volume at the beginning of this manoeuvre ("FRC"), patient effort, flow limitation and exhalation time will all influence the magnitude of each ERV measurement. It is recommended that three satisfactory ERV manoeuvres be performed and the mean value reported. Factors that lead to unsatisfactory manoeuvres include cough, glottal closure, gas leak from the nose or mouth and too brief effort.

During each ERV manoeuvre, once RV has been reached, the patient should be coached to inhale completely to TLC. The observer should monitor patient performance to ensure a maximal effort. Three satisfactory IVC manoeuvres should be obtained and the largest reported. Spirometer temperature should be recorded to correct the ERV and IVC to BTPS.

\section{Calculations}

The lung volume $(V \mathrm{~L})$ of the patient when connected to the spirometer is obtained as follows:

$$
\begin{aligned}
& V_{\mathrm{L}}=V_{\mathrm{air}} \cdot F_{\mathrm{sp}, \mathrm{He}, 1} / F_{\mathrm{sp}, \mathrm{He}, 3} \\
& \left(F_{\mathrm{sp}, \mathrm{He}, 2}-F_{\mathrm{sp}, \mathrm{He}, 3)}\right)\left(F_{\mathrm{sp}, \mathrm{He}, 1}-F_{\mathrm{sp}, \mathrm{He}, 2}\right)-V_{\mathrm{ds}}
\end{aligned}
$$

where $F_{\mathrm{sp}, \mathrm{He}, 3}$ is the helium concentration at the end of the determination and $V \mathrm{ds}$ is the valve and mouthpiece deadspace.

The temperature and water vapour saturation of gas in the calibrating syringe should be used to convert the FRC results to BTPS conditions. The ERV, IC and IVC should be corrected to BTPS according to the temperature inside 
the spirometer and fully saturated gas. This is true even for dry spirometers as the gas within the spirometer is saturated with water vapour from the lungs during the measurements.

Residual volume and TLC are obtained from: RV = FRC - ERV (where ERV is the mean of several efforts) and TLC $=$ RV + IVC (the preferred method), but TLC = $\mathrm{FRC}+\mathrm{IC}$ and RV = TLC - IVC are also acceptable. Variation in ERV will depend on how FRC varies from manoeuvre to manoeuvre as well as on the effort used to reach RV. A previous recommendation has been that ERV be taken as the largest of several efforts [14]. However, the largest ERV may be due merely to the largest starting FRC and its use will bias the results toward the least RV and least TLC. We consider that it is approp- riate to account for spontaneous variation in FRC and the start of the ERV manoeuvre and thus recommend the use of the mean ERV of three acceptable manoeuvres.

\section{Reproducibility and needs for duplicate analyses}

At present, little information is available in the literature upon which to base reproducibility standards for the helium dilution method for measurement of FRC for either clinical or research purposes and upon which to base recommendations for the number of tests that should be performed in each patient. Here, we have made a first attempt, but anticipate review and appropriate revision in the future. Pertinent issues in this regard include: the magnitude of change that is of clinical relevance; time constraints in busy laboratories; actual reproducibility obtained in laboratories utilizing highly trained technicians; differences amongst equipment made by different manufacturers; how reproducibility is affected by patient stature; age and disease state; and how much time is required for helium washout to occur between measurements.

Same-day duplicate measurements of FRCs using multiple breath helium dilution in an epidemiological study had coefficients of variation $(\mathrm{CVs})$ of $5 \%$, with only slightly larger CVs (e.g. 6.0\%) in patients with chronic obstructive pulmonary disease (COPD) ([6]: data are in unpublished appendices on page 105). These results were confirmed in an analysis of data from two clinical laboratories using similar equipment and the methodology described in the present paper. In each laboratory 50 consecutive patients were studied, many with severe airways obstruction. For these patients (mean FRC of $3.09 \mathrm{~L}$ ), the $95 \%$ confidence limits for differences between duplicate measurements were $\pm 400 \mathrm{~mL}$. Eighty six per cent of the patients had differences between duplicates smaller than $200 \mathrm{~mL}$ (R. Brown, personal communication). Available data do not allow us to say whether the expected variability is better expressed in absolute volumes or as a percentage of the observed. Average time between duplicate FRC measurements was $5 \mathrm{~min}$ in one laboratory and 8 min in the other. Any helium retained in the lungs between tests would have caused the second FRC measurement to be systematically less than the first. This was not the case in either laboratory.

On the basis of this information, it is recommended that the number of FRC determinations be tailored to fit the reason why the measurement is being made. For some clinical circumstances, a single measurement may be suf- ficient. For example, a patient who is being evaluated for pneumonectomy and in whom the FRC and TLC are found to be within the normal range in the first measurement need not have a second one because a difference of about $400 \mathrm{~mL}$ in either will not affect the clinical decision. On the other hand, it is recommended that two FRC determinations be done when accuracy is of particular importance, such as when patients are being evaluated for the presence of changes over a period of time. If the values agree within $200 \mathrm{~mL}$, the mean should be reported. If they do not, a third measurement should be made and the mean of the two closest values reported. In individual laboratories, it should be verified that FRC values are reproducible to within $200 \mathrm{~mL}$ about $85 \%$ of the time. Errors of less than $200 \mathrm{~mL}$ in FRC are negligible since expected individual variation (e.g. related to posture, meals, type of clothing, time elapsed since last use of bronchodilator, flow limitation in patients with severe airways obstruction, etc.), and predicted normal ranges are much greater than that.

Systems should allow the technician to perform at least three tests. Time since the last test ideally should be sufficient to allow virtually complete washout of helium from the previous test. This will vary with factors such as lung size (patients with large FRCs will have lower lung helium concentrations at equilibration than patients with small FRCs), type and severity of lung disease and total ventilation relative to FRC between the FRC measurements. In some laboratories, spirometry is performed between FRC determinations and this will probably reduce washout time but may also affect the FRC, in particular in patients with reactive airways. At present, the helium meters used in FRC determinations are not readily accessible for measurement of helium concentration in expired gas just prior to a test. Simple design changes could remedy this. As an approximation, a residual helium concentration of $0.1 \%$ would lead to an error in the second FRC of $\sim 60 \mathrm{~mL}$ (Appendix 2), an amount of no significance.

The issues outlined previously with regard to reproducibility standards apply also, for the most part, to measurements of TLC and subdivisions thereof. Little rigorous guidance is available in the literature. For determination of ERV, most systems allow the measurement to be made once the FRC measurement is complete without removing the patient from the mouthpiece. Whether the value ERV determined in this way is systematically different from that obtained following a brief period off the mouthpiece is unknown, but it appears unlikely.

\section{Paths of helium loss and effect of nitrogen excretion}

Paths of helium loss during the test include helium dissolution in the water of the spirometer, equipment leaks, leaks around the noseclip and mouthpiece, transfer through ruptured tympanic membranes, swallowing and absorption into the fluids and tissues of the body. Helium loss during the test leads to overestimation of FRC. Continued helium loss leads to failure to achieve equilibration as it has been defined (except in the instance of extremely small leaks), and also causes overestimation of FRC. The effect of dissolution in water is negligible. Equipment should be tested for leaks as previously 
outlined. Technicians should ask patients about a history of ruptured tympanic membranes and should be sensitive to the possibility of improperly sealed noseclips and mouthpieces and to swallowing by the patients during the tests.

Absorption of helium will be affected by the initial helium concentration, the alveolar helium concentration (initially zero but increasing rapidly during equilibration), cardiac output, total body water and fat and the duration of the test. Opinions and recommendations vary as to how to account for the effect of helium absorption, if at all. Based on theoretical considerations, it has been recommended that $100-110 \mathrm{~mL}$ be subtracted from the FRC value obtained [1, 18]. Another investigator argued that the correction for helium absorption could be based only on very approximate estimates and chose to omit a correction [17]. In a study of the time-related disappearance of helium from the helium dilution system in two normal subjects, it was concluded that for a 7 min procedure, the correction in FRC should be $105 \mathrm{~mL}$ [24]. A graphical solution to the problem by extrapolation of the concentration-time curve to the beginning of the alteration in gas concentration was proposed [25] but subsequently rejected [14].

Problems with these various assessments include use of helium meters that were less accurate than those now available, assumptions of constant FRC during the study as well as unimpaired gas mixing and accurate replacement of oxygen consumption, and failure to consider the effects of nitrogen excretion. Although nitrogen excretion has been estimated at as much as $30 \mathrm{~mL} \cdot \mathrm{min}^{-1}$ during the nitrogen washout method for measuring FRC, it must be considerably less during the helium dilution test because the alveolar to spirometer gradient for nitrogen is much smaller. To the extent that nitrogen excretion occurs, it tends to increase system volume, dilute the helium and lead to an overestimation of FRC. However, in systems using the multiple bolus method for addition of oxygen, such increases in system volume and dilution of helium do not occur (see first example of problems in intermittent addition of oxygen, below). With the system using constant flow of oxygen, the correction performed at the end of the procedure to account for an oxygen supply that is different from oxygen consumption also accounts for the effect of nitrogen excretion (see first example of problems in steady oxygen flow, below). Thus, in neither method is correction for nitrogen excretion necessary. The effect of helium absorption is a small overestimation of FRC. Systematic correction would be desirable. However, uncertainty as to the exact magnitude of the correction and the variability from patient to patient leads us to recommend that no correction be made until better data are available.

\section{Other factors affecting helium concentration}

Correction has been recommended when carbon dioxide production $\left(V^{\prime} \mathrm{CO}_{2}\right)$ is less than oxygen consumption $\left(V^{\prime} \mathrm{O}_{2}\right)(\mathrm{R}<1)$ [18]. Such a difference would mean that helium would be concentrated in the lung and, at "equilibration", the concentration in the lung actually would be greater than in the spirometer. The error due to this depends on $\mathrm{R}$ and the relative volumes of lung and spirometer and is certain to be extremely small (see Appendix
3). When $\mathrm{R}$ is less than one, the measured FRC will be overestimated. However, it is not at all clear what the value of $\mathrm{R}$ actually is during the test. Some patients may hyperventilate and have an $\mathrm{R}>1$ leading to an underestimation of FRC. Because $\mathrm{R}$ is not measured and the effect of it is negligible, it is recommended that no correction be made.

\section{Switching error and changes in lung spirometer volume during the test}

In practice, patients are not always switched into the spirometer circuit exactly at the end-expiratory level so that lung volume is not equal to the FRC. Corrections for this should be made when reporting FRC (fig. 1). Some computerized equipment reports and accounts for the "switch-in-error" automatically.

During the measurement, the patient's actual FRC may be stable or may vary steadily or intermittently. Such variations do not change the total volume of the system (spirometer plus lung) or affect the rate at which oxygen is added in systems using constant flow equal to the patient's estimated oxygen consumption. Such systems typically measure the lung volume when the patient is switched into the equipment, but variations in FRC during the test may lead to errors (see examples, below). In systems in which oxygen boluses are added to keep spirometer volume constant at end-expiration, variations in actual FRC during the test affect the rate at which oxygen is added. During the test, when the patient's actual FRC decreases (as is often the case [26]) or increases (e.g. when patients with severe airways obstruction and dynamically determined FRC are encouraged to take deep breaths intermittently to reduce equilibration time), the added oxygen will be less than or greater than oxygen consumption, respectively. This will lead to underestimation or overestimation, respectively, of FRC at switch-in. In fact, such systems measure the FRC at the end of the test (at switch-out).

The following examples illustrate problems that may be encountered with intermittent addition of oxygen:

1) In this example (fig. 2), the patient's FRC decreases noticeably during the first few breaths and then remains

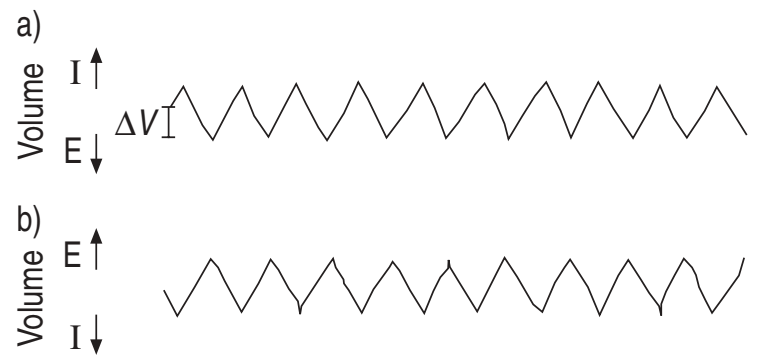

Time

Fig. 1. - Volume of a) lung and b) spirogram as a function of time in a subject connected to the spirometer at a level that was not a representative end-expiratory volume. Functional residual capacity (FRC) is constant and steady oxygen flow is added at a rate equal to oxygen consumption so that the end-expiratory volume of the spirometer is constant. FRC should be reported as the lung volume measured by gas dilution corrected for switch-in error $(\Delta V)$ (see text). I: inspiration; E: expiration. 


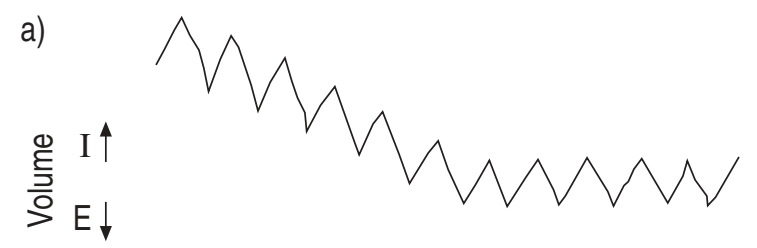

b)

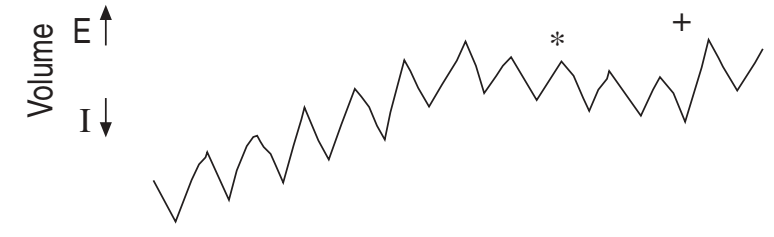

Time

Fig. 3. - Volume of a) lung and b) spirogram during intermittent addition of oxygen. The patient's FRC decreases noticeably during the first several breaths and then remains stable (see text). *: slope here is due to oxygen consumption; +: oxygen is added to the spirometer. For definitions see legend to figure 1 .

stable. During the first phase, spirometer volume is increasing and oxygen will not be added because the "interpretation" of the equipment will be that there is no oxygen consumption. When FRC becomes stable, oxygen is added in an amount equal to oxygen consumption (ignoring helium absorption and nitrogen excretion). At the end of the test, the total amount of oxygen added will be less than the actual oxygen consumption and the final helium concentration will be proportionately greater. The reported FRC will be less than the FRC at switch-in. From this, it is apparent that systems that add oxygen to keep spirometer volume constant give the FRC at the end of the test, i.e., switch-out volume rather than switch-in volume.

2) In this example (fig. 3), there is a switch-in error and the patient's FRC steadily increases during the test (perhaps due to increased ( $\left.V^{\prime} \mathrm{E}\right)$ in a patient with severe airways obstruction who is made anxious by the duration of the test). Here, spirometer volume will tend to decrease at a rate equal to the sum of the increase in the patient's

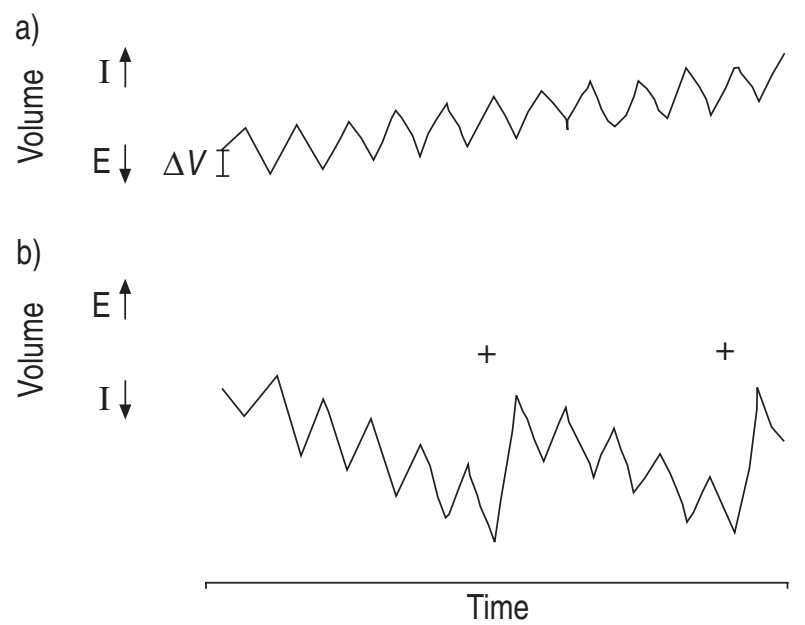

Fig. 2. - Volume of a) lung and b) spirogram during intermittent addition of oxygen. There is a switch-in error $(\Delta V)$ and the patient's FRC increases steadily during the test (see text). + : oxygen is added to the spirometer. For definitions see legend to figure 1.
FRC, oxygen consumption and helium absorption. Nitrogen excretion will tend to increase spirometer volume. To keep spirometer volume constant at end-exhalation, oxygen will be added in excess of the sum of oxygen consumption plus helium absorption minus nitrogen excretion, the volume of the spirometer plus lung will increase, the final helium concentration will be proportionately decreased and switch-out volume will be reported. The effect of nitrogen excretion will have been accounted for by the rate at which oxygen was added to the circuit. It is clear that a correction of the reported switch- out volume for the switch-in error makes no sense because the correction is not being made in relation to FRC at the beginning of the test.

In some laboratories, it is the practice to encourage patients to make intermittent deep inhalations during the test. The purposes are to encourage gas mixing in regions of relatively poor ventilation and to decrease equilibration time. Following a deep inhalation, however, a patient with severe airways obstruction may take many breaths before returning to the original FRC. As illustrated in this example, this will lead to errors in the amount of oxygen added during the procedure so the practice is not recommended, at least in patients with considerable airways obstruction.

The following examples illustrate problems that may be encountered with steady oxygen flow:

1) In this example (fig. 4), there is a switch-in error and the patient's FRC is steady. The estimate of the $V^{\prime} \mathrm{O}_{2}$ that is being added to the spirometer exceeds the actual $V^{\prime} \mathrm{O}_{2}$, spirometer volume increases steadily, the final helium concentration is proportionately decreased and the reported FRC will be too great. The correction can be made simply by subtracting the increment in spirometer volume that took place during the test $(\mathrm{C})$ from the FRC that is obtained. This correction also accounts for increases in system volume due to nitrogen excretion. Here, it can be seen that this method gives the switch-in FRC. Correction for switch-in-error is appropriate.

2) This example (fig. 5) demonstrates the potential for error with the method using steady $\mathrm{O}_{2}$ flow. Here, the estimated $V^{\prime} \mathrm{O}_{2}$ was correct but it was not apparent to the technician that the FRC of the patient decreased during the test. In this case, the final helium concentration would provide the correct FRC at switch-in because total volume (lung plus spirometer) did not change. However, the

a)

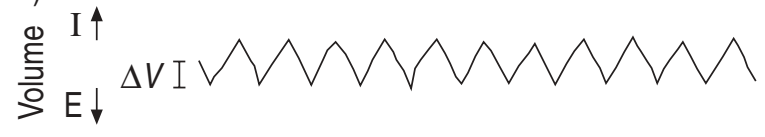

b)

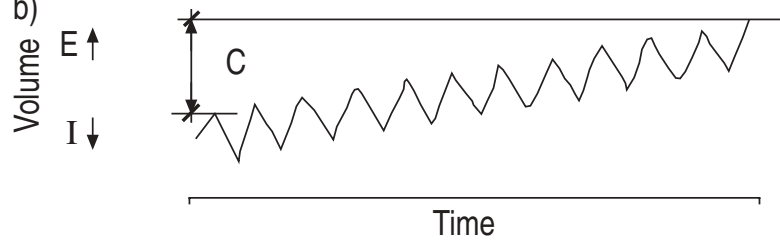

Fig. 4. - Volume of a) lung and b) spirogram during steady oxygen flow. There is a switch-in error $(\Delta V)$ and the patient's FRC is steady (see text). $\mathrm{C}$ : correction in calculated FRC (the correction is the increment in spirometer volume during the test). For further definitions see legend to figure 1. 


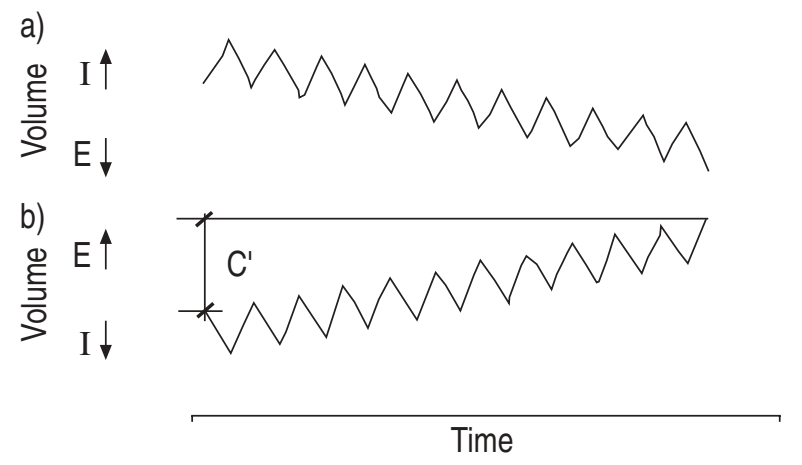

Fig. 5. - Volume of a) lung and b) spirogram during steady oxygen flow. The patient's FRC decreases during the test and the oxygen flow is the same as oxygen consumption (see text). $\mathrm{C}^{\prime}$ : correction made in calculated FRC. For further definitions see legend to figure 1.

spirometer trace makes it appear that excess $\mathrm{O}_{2}$ was added. When the correction $\left(\mathrm{C}^{\prime}\right)$ is made, the reported FRC becomes less than the FRC at switch-in. In fact, it becomes the switch-out FRC.

Errors in oxygen supply can be prevented by continuously measuring the oxygen concentration. At the same time this provides a means to adjust the output of thermal conductivity helium analysers for the effect of different oxygen concentrations and to assure a satisfactory $\mathrm{F}, \mathrm{O}_{2}$. To date, we know of no reports of significant hypoxaemia during helium dilution tests and, therefore, do not recommend routine use of pulse oximetry.

It is not self-evident which FRC (switch-in versus switch-out) is of greatest interest, if either. Undoubtedly, people have different FRCs at different times; that is a biological fact. During the measurements, one could imagine changes in FRC due to relaxation or contraction of muscles (e.g. abdominal muscles), shifts in posture between measurements and changes in $V^{\prime} \mathrm{E}$, of particular relevance in patients whose FRCs are determined dynamically. In this regard, it might be useful if $V^{\prime} E$ during the measurement was provided so that FRC could be related to it and so that changes in FRC between measurements might be understood more clearly.

\section{Quality control}

All quality control checks should be retained for review and trend analysis.

\section{Daily quality control checks}

Before each patient is tested, the following items should be checked: water level, all absorbers, helium analyser sample flow rate, oxygen tank pressure, operation of the circulating fan (by listening) and the baseline stability of helium and volume signals.

Systems that can be pressurized conveniently (e.g. by putting weights on the spirometer bell) should be checked for leaks at least once during the $24 \mathrm{~h}$ prior to patient testing and after tubing or canister changes. Inject about $3 \mathrm{~L}$ of air into the system, close the breathing valve, then pressurize the breathing circuit to about $0.4 \mathrm{kPa}(4$ $\mathrm{cmH}_{2} \mathrm{O}$ ). With the system closed and the circulating fan operating, there should be no detectable leaks (volume change) over a span of $3 \mathrm{~min}$.
The technician should document the following for each patient: history of eardrum perforation; problems with leaks around the mouthpiece and noseclip; excessive swallowing during the test; posture changes; and apparent degree of effort during the IVC and ERV manoeuvres.

The resulting volume/time tracings should be examined for evidence suggesting sudden or slow inward or outward leaks and for reproducibility of the end-tidal volumes, ICs and IVCs. A difference between switch-in and switch-out volumes of more than $0.3 \mathrm{~L}$ suggests the presence of a leak.

A calculated system equipment volume should be compared with prior measurements that establish the normal range for that instrument. Values that fall outside the normal range should be brought to the operator's attention as possibly indicating a leak (or a change in the water level or amount of carbon dioxide absorber).

The time to equilibration (or the lack of equilibration after $10 \mathrm{~min}$ ) should be reported. Ideally, the shape of the helium/time signal should also be examined for a smooth decline and plateau during the test. In most subjects, helium will equilibrate more rapidly if deep breaths are taken intermittently. However, if the equilibration times or the difference between plethysmographic or radiological volumes and helium dilution volumes are used to assess disease severity, intermittent deep inspirations during equilibration will alter the results. Deep breaths may also affect the results in patients with dynamically determined FRCs as described in the section on switching error. Hence, equilibration during regular tidal breathing is recommended for patients who do not return to their previous FRCs within three breaths of a deep inhalation.

The software should allow the technician to exclude individual tests (after review of quality checks and reproducibility) and report the average FRC and RV from the remaining acceptable tests.

\section{Weekly checks}

The stability of the helium meter should be confirmed. The meter reading should not drift more than $0.02 \%$ for up to $10 \mathrm{~min}$. The temperature sensor should be checked to ensure that it remains accurate to within $0.5^{\circ} \mathrm{C}$. After overnight equilibration with the room, spirometer temperature can be compared to room temperature with a thermometer known to be accurate to within $0.1^{\circ} \mathrm{C}$.

\section{Linearity check}

To establish the linearity of the helium meter, the spirometer is thoroughly flushed with air until the meter reading is stable. With the spirometer in its lowest position,

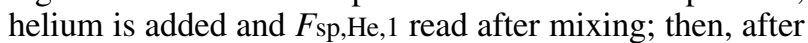
the addition of a precisely known volume of air with a syringe, the initial spirometer volume is calculated from

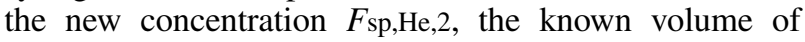
added air and $F_{\mathrm{sp}, H e, 1}$. Then, more air is introduced with the syringe and new computations are performed; this is repeated until the spirometer is full. BTPS corrections should not be made for these computations. Volumes added with the syringe and calculated volumes should agree within $3 \%$ and be related linearly with a regression coefficient $>0.90$. Modern helium meters tend to remain 
linear. Once stability has been demonstrated by relatively frequent checks over a few months, then quarterly or semi-annual checks seem sufficient. We have no satisfactory basis for specifying an interval. The linearity test described allows verification of more than just the helium meter. For example, after each addition of the precisely known volume of air, the volume signal from the spirometer can be checked.

The integrity of the system is actually checked with each measurement of FRC. From test to test, the system should perform consistently during the setup procedures. For example, $V_{\text {sp }}$ (given automatically in many systems) and the second helium concentration (after addition of air) should be very reproducible (although the latter is not a substitute for a linearity check of the meter over its entire range). During setups, departures by as little as $0.1 \%$ helium or changes in $V$ sp greater than $3 \%$ of mean suggest the possibility of technical problems such as incorrect gas volume having been added, a leak, or meter dysfunction. In practice, the latter is very uncommon.

\section{Biological check}

Periodic testing (e.g. once monthly) of a laboratory "reference" subject is useful [27] in that it tests not only the equipment, but also the procedures used by technicians. Criteria for "out-of-limits" tests vary between different subjects tested and the degree of precision desired. Data related to variability within and among subjects are provided in a separate paper on reproducibility of lung volume measurements [28].

\section{Cross contamination}

Steps to minimize the risk of cross-contamination [29] include:

1) Technicians must wash their hands before and after each patient is tested and wear gloves during the procedure. A disinfected mouthpiece and breathing valve should be used for each patient. A clean absorbent towel should be placed beneath the mouthpiece during the test. The towel and patient secretions (saliva) should be disposed of at the end of the test.

2) The breathing circuit should be opened to the room and the system blower run for $10 \mathrm{~min}$ after testing each patient, to promote drying.

3) At the end of each testing day, the breathing circuit tubing and valves should be disassembled. The tubing, valves and rubber mouthpieces should be disinfected as follows: wash with detergent, soak in activated glutaraldehyde (or other equivalent disinfectant), rinse and hang to dry overnight.

4) Water from sealed spirometers should be drained at the end of each week and the spirometer allowed to dry over the weekend.

\section{Comparison of the helium dilution method and body plethysmography}

Since its development, the body plethysmograph has been considered the best method for measuring the volume of gas in the lungs. In healthy subjects and patients with airways obstruction, the plethysmographic method typically gives values greater than the helium dilution method [30-33]. The traditional view has been that the latter underestimates lung volume because lung regions with long time constants do not reach equilibration with the rest of the lung and spirometer at the end of the test. Indeed, differences in FRC obtained plethysmographically and by helium dilution have been used to estimate the volume of "trapped" gas in the lung. Based on recent data, the traditional view should be reassessed.

There are three known mechanisms by which ple- thysmography can overestimate lung volume. One occurs when abdominal gas is compressed and decompressed in synchrony with thoracic gas [31]. Another is related to nonhomogeneous alveolar pressure swings during the "Boyle's law manoeuvre" [34-36]. These two mechanisms have been estimated to have the potential to lead to as much as a $10 \%$ overestimation of lung volume when determined plethysmographically, but detailed studies in large numbers of patients have not been done. The third mechanism appears to be most substantial. It is now recognized that, during the Boyle's law panting manoeuvre, flow occurs between the thorax and extra-thoracic airways. In the presence of airways obstruction this leads to significant pressure losses between alveoli and the airway opening. The result is an overestimation of lung volume because the plethysmographic method takes pressure changes at the airway opening to represent alveolar pressure changes. The magnitude of the overestimation depends on the panting frequency, the severity of the airways obstruction and the compliance of the extra-thoracic airways [36-38]. In some individuals, thoracic gas volume determined plethysmographically at slow panting frequencies $(<1 \mathrm{~Hz})$ is as much as $2 \mathrm{~L}$ less than at spontaneous panting frequencies (usually in the range of $2-4 \mathrm{~Hz}$ ). Although, this overestimation of lung volume determined plethysmographically has been considered in some prior comparisons with the helium dilution method [32, 39], it is clear that further research is required in this area.

\section{Appendix 1}

The effect of a given change in helium concentration (e.g. $0.01 \%$ ) on the calculation of FRC will vary with the characteristics of the equipment and the volumes of the various gases added to the spirometer before the patient is connected to the apparatus. By conservation of mass:

$$
(\mathrm{He} 2)\left(V_{\mathrm{He}, \mathrm{O}_{2}}, \mathrm{air}+V_{\mathrm{eq}}\right)=(\mathrm{He} 3)\left(V_{\mathrm{He}}, \mathrm{O}_{2}, \mathrm{air}+\mathrm{Veq}+\mathrm{FRC}\right)
$$

where $\mathrm{He} 2=$ helium concentration in the equipment prior to turn in; $V \mathrm{He}, \mathrm{O}_{2}$,air = sum of the volumes of helium, $\mathrm{O}_{2}$ and air; $\mathrm{He} 3=$ helium concentration at end of test; Veq = equipment volume; and FRC = functional residual capacity. It then follows that:

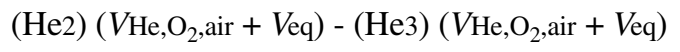

$$
\begin{aligned}
& \mathrm{FRC}=\frac{\mathrm{He} 3}{\mathrm{H}}
\end{aligned}
$$

In a typical system, $V \mathrm{He}, \mathrm{O}_{2}$,air $=5.0 \mathrm{~L}, V_{\text {eq }}=3.5 \mathrm{~L}$ and $\mathrm{He} 2=7.0 \%$. If $\mathrm{He} 3$ is $5 \%$, FRC would be calculated as $3.40 \mathrm{~L}$. If $\mathrm{He} 3$ is $4.99 \%$, FRC would be calculated as 3.42 $\mathrm{L}$, a difference of $20 \mathrm{~mL}$. 


\section{Appendix 2}

If, after an initial measurement of FRC, some helium remains in the lung when a second measurement is initiated, the second measured FRC will be systematically underestimated. A residual helium concentration of $0.1 \%$ would produce a negligible error. At the end of a test, the helium concentration in the spirometer is as follows:

$$
\mathrm{He} 3=\frac{V \mathrm{He}}{V \mathrm{He}, \mathrm{O}_{2}, \text { air }+V_{\text {eq }}+\mathrm{FRC}}
$$

where $\mathrm{He} 3$ = concentration of helium in the spirometer at the end of the test, $V \mathrm{He}=$ volume of helium added, $V \mathrm{He}, \mathrm{O}_{2}$,air $=$ sum of the volumes of helium, $\mathrm{O}_{2}$ and air added, $V$ eq $=$ equipment volume and FRC: $=$ functional residual capacity. In a typical system, $V \mathrm{He}=0.6 \mathrm{~L}, V \mathrm{He}, \mathrm{O}_{2}$, air $=5.0 \mathrm{~L}$ and $V \mathrm{eq}=3.5 \mathrm{~L}$.

If $\mathrm{FRC}=3.40 \mathrm{~L}, \mathrm{He} 3$ would be $5.04 \%$.

If FRC is $3.40 \mathrm{~L}$ and $0.1 \%$ helium remains in the lung then there would be an additional $3.4 \mathrm{~mL}$ helium in the system (total helium $=0.6034 \mathrm{~L}$ ) and the final helium concentration would be $5.07 \%$, i.e. the difference would be $0.03 \%$. From Appendix 1, this represents an error of about $60 \mathrm{~mL}$ which is negligible.

\section{Appendix 3}

The effect of $\mathrm{R}$ (i.e. $V^{\prime} \mathrm{CO}_{2} / V^{\prime} \mathrm{O}_{2}$ ) on FRC determined by the helium dilution method can be analysed as follows. In a steady state (such as at the end of the test), by conservation of mass:

$$
V^{\prime} \mathrm{I}, \mathrm{A} \cdot F \mathrm{I}, \mathrm{He}=V^{\prime} \mathrm{E}, \mathrm{A} \cdot F \mathrm{~A}, \mathrm{He}
$$

where $V^{\prime} \mathrm{I}, \mathrm{A}=$ inspired alveolar ventilation, $F \mathrm{I}, \mathrm{He}=$ fractional concentration of inspired helium, $V^{\prime} \mathrm{E}, \mathrm{A}=$ expired alveolar ventilation, $F \mathrm{~A}, \mathrm{He}=$ fractional concentration of alveolar helium. Thus, it follows that:

$$
F \mathrm{~A}, \mathrm{He}=F \mathrm{I}, \mathrm{He} \cdot \frac{V^{\prime} \mathrm{I}, \mathrm{A}}{V^{\prime} \mathrm{E}, \mathrm{A}}
$$

For conditions in which $\mathrm{R}$ is $<1, V^{\prime} \mathrm{I}, \mathrm{A} / V^{\prime} \mathrm{E}, \mathrm{A}$ is $>1$ and $F$ A,He must be greater than $F \mathrm{I}, \mathrm{He}$. $F \mathrm{I}, \mathrm{He}$ is used to calculate FRC. When $\mathrm{R}$ is $<1$, FRC will be overestimated. When $\mathrm{R}$ is $>1$, FRC will be underestimated.

At a given $V^{\prime} \mathrm{I}, \mathrm{A}$, the difference between $F \mathrm{I}, \mathrm{He}$ and $F \mathrm{~A}$, He depends on the difference between $V^{\prime} \mathrm{O}_{2}$ and $V^{\prime} \mathrm{CO}_{2}$. The significance of this difference in correcting FRC depends on the relative volumes of the lung and the spirometer. The correct helium concentration to use in calculating FRC would be that found after complete equilibration of gas in the lung and spirometer. If the spirometer is large relative to the lung the correction in FI,He will be small. If the spirometer is small relative to the lung, the correction will be large.

To put this in perspective, some representative values are given here. If $V^{\prime} \mathrm{I}, \mathrm{A}=5,000 \mathrm{~mL}, V^{\prime} \mathrm{CO}_{2}=200 \mathrm{~mL}, V^{\prime} \mathrm{O}_{2}$ $=250 \mathrm{~mL}(\mathrm{R}=0.8)$, then $V^{\prime} \mathrm{E}, \mathrm{A}$ will be $4,950 \mathrm{~mL}$ and $F \mathrm{~A}$,He will be greater than $F \mathrm{I}$,He by the ratio 5,000/4,950, or $1 \%$. A typical spirometer system has a volume of $8.5 \mathrm{~L}$ (helium, oxygen, air, equipment volume) and helium concentration of $7.0 \%$ when the patient is turned in for FRC measurement. If the $F \mathrm{I}, \mathrm{He}$ at the end of the test is $4.66 \%$, the FRC will be calculated to be $4.25 \mathrm{~L}$ and $F \mathrm{~A}$,He will be $4.66 \times 1.01=4.71 \%$. If gases in the equipment and spirometer $\left(\mathrm{VHe}, \mathrm{O}_{2}\right.$,air $)$ and lung are allowed to equilibrate, the helium concentration will be:

$\left(\mathrm{FRC} \cdot F \mathrm{~A}, \mathrm{He}+V \mathrm{He}, \mathrm{O}_{2}\right.$, air $\left.\cdot F \mathrm{I}, \mathrm{He}\right)$

$F \mathrm{He}, \mathrm{eq}=\frac{\mathrm{FRC}+\mathrm{VHe}, \mathrm{O}_{2}, \text { air }}{\mathrm{Fin}}$

where $V \mathrm{He}, \mathrm{O}_{2}$,air = sum of the volumes of helium, $\mathrm{O}_{2}$ and air added and $F \mathrm{He}$,eq $=$ helium concentration after equilibration. In this example, $F \mathrm{He}$,eq $=4.68 \%$. It has been assumed that FRC is exactly $4.25 \mathrm{~L}$, although this is slightly incorrect because it has been calculated from $F \mathrm{I}$,He and not from $F_{\mathrm{He} \text {,eq }}$ which is never known. The FRC would have been calculated using $4.66 \%$ rather than $4.68 \%$ and the error would have been $40 \mathrm{~mL}$. For the same $\mathrm{R}$, the error would be greater if $V^{\prime} \mathrm{O}_{2}=500 \mathrm{~mL}$ and $V^{\prime} \mathrm{CO}_{2}=400 \mathrm{~mL}$.

\section{References}

1. Meneely GR, Kaltreider NL. The volume of the lung determined by helium dilution: description of the method and comparison with other procedures. J Clin Invest 1949; 28: 129-139.

2. Andersson LG, Ringqvist I, Walker A. Total lung capacity measured by body plethysmography and by the helium dilution method: a comparative study in different patient groups. Clin Physiol 1988; 8: 113-119.

3. Brugman TM, Morris JF, Temple WP. Comparison of lung volume measurements by single breath helium and multiple breath nitrogen equilibration methods in normal subjects and COPD patients. Respiration 1986; 49: 52-60.

4. Cogswell JJ, Hull D, Milner AD, Norman AP, Taylor B. Lung function in childhood. II. Thoracic gas volumes and helium functional residual capacity measurements in healthy children. Br J Dis Chest 1975; 69: 118-124.

5. DuBois AB, Botelho SY, Bedell GN, Marshall R, Comroe $\mathrm{JH}$ Jr. A rapid plethysmographic method for measuring thoracic gas volume: a comparison with nitrogen washout method for measuring functional residual capacity in normal subjects. J Clin Invest 1956; 35: 322-326.

6. Ferris BG. Comparison of five methods for determination of FRC and TLC in 100 persons. Am Rev Respir Dis 1978; 118: 92-111.

7. Ibanez J, Raurich JM, Moris SG. Measurement of functional residual capacity during mechanical ventilation. Comparison of a computerized open nitrogen washout method with a closed helium dilution method. Intensive Care Med 1983; 9: 91-93.

8. Reichel G. International symposium on body plethysmography, differences between intrathoracic gas measured by the body plethysmograph and functional residual capacity determined by gas dilution methods. Prog Resp Res 1969; 4: 188-193.

9. Rodarte JR, Hyatt RE, Westbrook PR. Determination of lung volume by single- and multiple-breath nirogen washout. Am Rev Respir Dis 1976; 114: 131-136.

10. Tierney DF, Nadel JA. Concurrent measurements of 
functional residual capacity by three methods. J Appl Physiol 1962; 17: 871-873.

11. Ries AL. Measurement of lung volumes. Clin Chest Med 1989; 10: 177-186.

12. Ries AL, Clausen JL. Lung volumes. In: Wilson A, ed. Pulmonary Function Testing: Indications and Interpretations. Orlando, Florida, Grune and Stratton, Inc., 1985; pp. 69-85.

13. Quanjer PH, Anderson LH, Tammeling GJ. Standardized lung function test. Chapter 2. Static lung volumes and capacities. Bull Eur Physiopathol Respir 1983; 19 (Suppl. 5): 11-21.

14. Quanjer PH, Tammeling GJ, Cotes JE, Pedersen OF, Peslin R, Yernault JC. Lung volumes and ventilatory flow. Report Working Party. Standardization of lung function tests. European Community for Steel and Coal and European Respiratory Society. Eur Respir J 1993; 6 (Suppl. 16): 5-40.

15. Gardner RM. Standardization of spirometry - 1994 update. Am Rev Respir Crit Care Med 1995; 152: 11071136.

16. Single-breath carbon monoxide diffusing capacity (transfer factor). Recommendation for a standard technique 1995 update. Official statement of the American Thoracic Society. Am J Respir Crit Care Med 1995; 152: 21852198.

17. Holmgren A. Determination of the functional residual volume by means of the helium dilution method. Scand $J$ Clin Lab Invest 1954; 6: 131-136.

18. Meneely GR, Ball COT, Kory RC, et al. A simplified closed circuit helium dilution method for the determination of the residual volume of the lungs. Am J Med 1960; 28: 824-828.

19. Krumpe PE, MacDannald HJ, Finley TN, Schear HE, Hall J, Cribbs D. Use of an acoustic helium analyzer for measuring lung volumes. J Appl Physiol 1981; 50: 203209.

20. Kauppinen Walin K, Sovijarvi AR, Muittari A, Usitalo A. Determination of functional residual capacity with 133xenon radiospirometry. Comparison with body plethysmography and helium spirometry: effect of body position. Scand J Clin Lab Invest 1980; 40: 347-354.

21. Larsson A, Linnarsson D, Jonmarker C, Jonson B, Larsson $\mathrm{H}$, Werner $\mathrm{O}$. Measurement of lung volume by sulfur hexafluoride washout during spontaneous and controlled ventilation: further development of a method. Anesthesiology 1987; 67: 543-550.

22. Yamamura T, Okamura A, Kikuchi N, Fukuda M, Kemmotsu $\mathrm{O}$. Measurement of functional residual capacity by sulfur hexafluoride washout. Masui 1992; 41: 925-931.

23. Hathirat S, Mitchell MD, Renzetti ADJ. Measurement of the total lung capacity by helium dilution in a constant volume system. Am Rev Respir Dis 1970; 102: 760-770.
24. Birath G, Swenson EW. A correction factor for helium absorption in lung volume determinations. Scand J Clin Lab Invest 1956; 8: 155-158.

25. Quanjer PH (Ed). Standardized lung function testing. Report Working Party, Standardization of lung function tests, European Community for Coal and Steel. Bull Eur Physiopathol Respir 1983; 19(Suppl. 5): 1-95.

26. Tammeling GJ. Residual volume and the function residual capacity (in Dutch). PhD Thesis, Gronigen, 1958.

27. Gardner RM, Clausen JL, Crapo RO, et al. Quality assurance in pulmonary function laboratones. Am Rev Respir Dis 1986; 134: 625-627.

28. Hankinson JL, Stocks J, Peslin R. Reproducibility of lung volume measurements. Eur Respir J 1998; (in press).

29. Clausen JL. Infectious disease precautions and measurements of absolute lung volumes. Eur Respir J 1997; 10: 2427-2431.

30. Schaanning CG, Gulsvik A. Accuracy and precision of helium dilution technique and body plethysmography in measuring lung volumes. Scand JClin Lab Invest 1973; 32: 271-277.

31. Brown R, Hoppin FGJ, Ingram RH Jr, Saunders NA, McFadden ERJ. Influence of abdominal gas on the Boyle's law determination of thoracic gas volume. J Appl Physiol 1978; 44: 469-473.

32. Brown R, Ingram RH Jr, McFadden ERJ. Problems in the plethysmographic assessment of changes in total lung capacity in asthma. Am Rev Respir Dis 1978; 118: 685692.

33. Rodenstein DO, Stanescu DC, Francis C. Demonstration of failure of body plethysmography in airway obstruction. J Appl Physiol 1982; 52: 949-954.

34. Brown R, Scharf S, Ingram RH Jr. Nonhomogeneous alveolar pressure swings in the presence of airway closure. J Lab Physiol 1980; 49: 398-402.

35. Brown R, Scharf SM, Ingram RH Jr. Nonhomogeneous alveolar pressure swings: effect of different respiratory muscles. J Appl Physiol 1982; 52: 638-641.

36. Brown R, Slutsky AS. Frequency dependence of plethysmographic measurement of thoracic gas volume. J Appl Physiol 1984; 57: 1865-1871.

37. Shore SA, Huk O, Mannix S, Martin JG. Effect of panting frequency on the plethysmographic determination of thoracic gas volume in chronic obstructive pulmonary disease. Am Rev Respir Dis 1983; 128: 54-59.

38. Rodenstein DO, Stanescu DC. Frequency dependence of plethysmographic volume in healthy and asthmatic subjects. J Appl Physiol 1983; 54: 159-165.

39. Rodenstein DO, Stanescu DC. Reassessment of lung volume measurement by helium dilution and by body plethysmography in chronic airflow obstruction. Am Rev Respir Dis 1982; 126: 1040-1044. 